\title{
Sperm whale diving behavior monitored using a suction-cup- attached TDR tag
}

\author{
Masao Amano ${ }^{1, *}$, Motoi Yoshioka ${ }^{2}$ \\ ${ }^{1}$ Otsuchi Marine Research Center, Ocean Research Institute, University of Tokyo, Akahama, Otsuchi, Iwate 028-1102, Japan \\ ${ }^{2}$ Faculty of Bioresources, Mie University, Kamihama, Tsu, Mie 514-8507, Japan
}

\begin{abstract}
The diving behavior of a medium-sized female sperm whale off the Kumano Coast, Japan, was studied using a suction-cup-attached TDR (time depth recorder) tag. The tag remained attached to the whale for $62 \mathrm{~h}$ and recorded 74 dives deeper than $100 \mathrm{~m}$. The whale repeatedly dived for 30 to $45 \mathrm{~min}$ down to $400-1200 \mathrm{~m}$. Surface intervals were generally 10 min between dives, except for a period of 1.3 to $4.2 \mathrm{~h}$ spent at the surface every afternoon. The whale spent long periods of time at the bottom of dives, during which there was considerable variability in both depth and velocity data, with occasional bursts in velocity. These data suggest that sperm whales use an active search-and-pursue strategy while foraging. Assuming all dives with active bottom time were for foraging, this whale spent about $80 \%$ of its total time in foraging dives. Dives with little activity at depth were occasionally observed, which were probably for resting. Although dive parameters resemble those of northern bottlenose whales, dive profiles seem to be different, suggesting that these 2 deep diving cetaceans employ different foraging strategies.
\end{abstract}

KEY WORDS: Sperm whale - Physeter macrocephalus · Diving behavior · Foraging · Time depth recorder

Resale or republication not permitted without written consent of the publisher

Sperm whales Physeter macrocephalus are remarkable divers in terms of both depth and duration; dives of large whales may reach over $2000 \mathrm{~m}$ and last for 60 min (Watkins et al. 1985, 1993). Over the years there has been a great deal of interest in the diving behavior of sperm whales as one of the potentially deepest mammalian divers. Recently, Watkins et al. (1993, 2002) used an acoustic transponder and radio telemetry tags and obtained detailed dive-depth profiles. However, relatively longer sampling intervals in their study hindered the understanding of detailed underwater behavior of the whales.

Deep dives of sperm whales are hypothesized to be for foraging (Rice 1989). Stomach contents recovered from whaling revealed that sperm whales feed on

*Email: amano@wakame.ori.u-tokyo.ac.jp medium- to large-sized mesopelagic squids as a primary prey in almost all oceans (Rice 1989). However, it remains unknown how sperm whales find and catch their prey in deep water. There are a few hypotheses. One is that they swim randomly with their mouths open and use tactile sense to find prey (Rice 1989). Another is the sit-and-wait strategy, which includes luring by the whale's white lip (Beale 1839), by bioluminescent mucosa from the squid prey attached around the mouth that may attract squids (Gaskin 1967), or by the stimulated bioluminescent organisms that flash due to the movement of whales (Fristrup \& Harbison 2002). The more accepted hypothesis is active searching using echolocation (Norris \& Harvery 1972, Mullins et al. 1988, Whitehead \& Weilgart 1991). However, some scientists believe that echolocation is not sufficient to detect squids whose density is close to seawater and insist that they depend on vision to a higher degree than that we believe (Fristrup \& Harbison 2002).

In order to determine the detailed movement pattern of whales, from which we could infer their foraging strategy, we used a suction-cup-attached TDR (time depth recorder) tag on a sperm whale off Japan in June 2000, and obtained $62 \mathrm{~h}$ of diving data. We report here some results from the data and discuss the characteristics of sperm whale diving behavior.

Materials and methods. The survey area was situated off the Kumano Coast in the southwestern part of Japan. Groups of sperm whales migrate into these waters in late spring to summer (May to September), and are frequently observed on the margin of the warm Kuroshio Current in the range of about $33^{\circ} 40^{\prime} \mathrm{N}$ to the north and $33^{\circ} 10^{\prime} \mathrm{N}$ to the south, ca. 20 miles (37 km) off the coast (Takahashi 2001).

We used a suction-cup-attached TDR tag similar to that employed in several other studies (Hooker \& Baird 1999, Baird et al. 2001, 2002). The tag body was made 
of synthetic foam containing a TDR (Wildlife Computers Mk6) and a VHF radio transmitter (ATS). An $8 \mathrm{~cm}$ diameter suction cup (Canadian Tire) was connected to the tag body by a plastic tube. The TDR was set to sample depth every second and velocity was sampled every $3 \mathrm{~s}$. The measurement range and resolution of the depth sensor were 0 to $2000 \mathrm{~m}$ and $8 \mathrm{~m}$, respectively. The tag weighed ca. $400 \mathrm{~g}$, and was deployed with a crossbow from a whale watching boat, 'Sueyoshi-maru' (15.8 m). After the tag was deployed, we followed the whale to observe its behavior, while trying to avoid any kind of disturbance.

Because the sperm whale's dive profile showed considerable depth ranges during the bottom part of the dive, the bottom of a dive is defined as the point where the profile shows an obvious bend (Boyd \& Arnbom 1991).

We calibrated the velocity data based on the methods of Blackwell et al. (1999). Due to the large resolution $(8 \mathrm{~m})$ of the depth record, we regressed average velocity to vertical depth change in $1 \mathrm{~min}$. Since the data size are too small to do Gaussian filtering, we regressed 3,5, 10, 15 and 20 percentile points of velocity data to corresponding vertical depth change rates, and took the line with the highest regression coefficients value. The r-values were relatively high, ranging from $0.974(5 \%)$ to $0.984(10 \%)$.

Results. We attached the tag to a whale measuring ca. $10 \mathrm{~m}$ length from a group of 7 whales at $07: 14 \mathrm{~h}$ on June 20, 2000. Using the zinc-finger gene DNA which was extracted from a skin sample retrieved from the suction cup, we determined that the whale was female. The members of the group were of a similar size and the group did not contain any calves. Just after the tag hit the body, the whale turned around and spyhopped, then dove down. When the whale returned to the surface, its behavior seemed normal and was not different to that of the other whales in the group. We followed the whale for about $5 \mathrm{~h}$ after deployment. The whale was around the $1000 \mathrm{~m}$ isobath in the morning, and moved northeast to where the water was deeper than $1500 \mathrm{~m}$ in the afternoon. We were unable to find the whale or the tag for the next $2 \mathrm{~d}$. After a search from the air, we found the tag floating 80 miles $(148.2 \mathrm{~km})$ away from the position where we tagged the whale, and recovered it $4 \mathrm{~d}$ after deployment.

From the TDR data, the tag was attached for $62 \mathrm{~h}$, and fell off the whale on the evening of the third day of

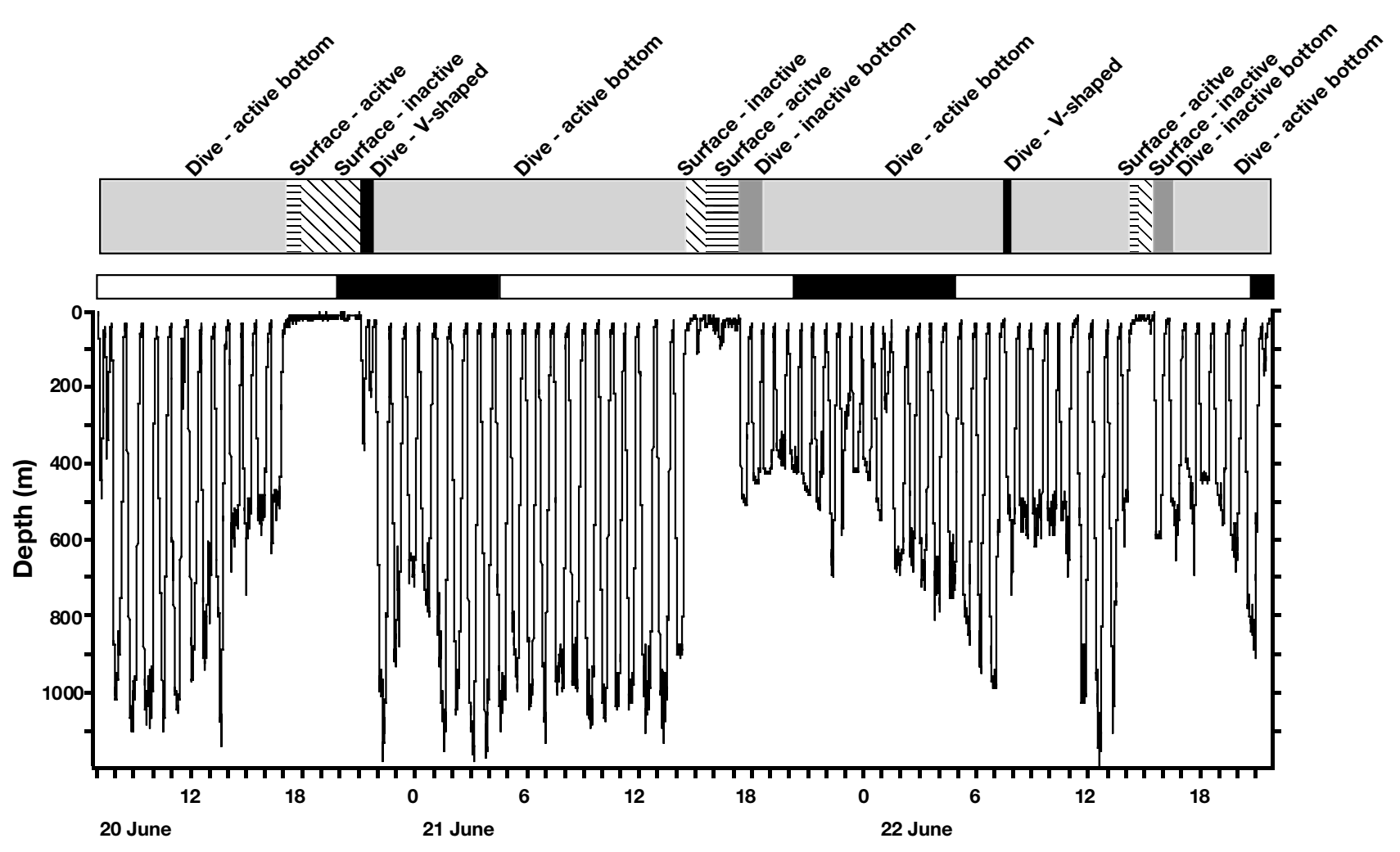

Fig. 1. Physeter macrocephalus. Whole dive depth profile and diving behavior sequences of tagged sperm whale. Black and white bars indicate day and night. Total time of each dive behavior pattern during tagged period was: dive-active bottom period, $49.1 \mathrm{~h}(80.0 \%$ of total time); dive-inactive bottom period, $2.8 \mathrm{~h}(4.5 \%)$; dive-V-shaped, $1.2 \mathrm{~h}(1.9 \%)$; surface-active, $3.7 \mathrm{~h}(6.0 \%)$; surface-inactive $4.6 \mathrm{~h}(7.6 \%)$ 


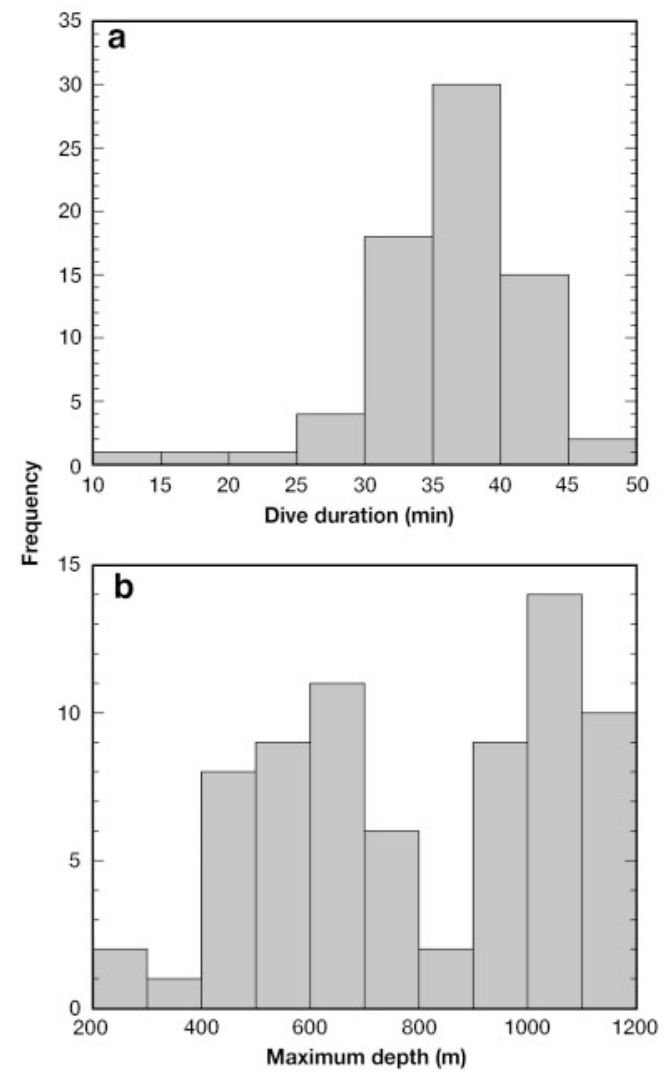

Fig. 2. Physeter macrocephalus. Frequency distributions of (a) dive duration and (b) maximum dive depth

attachment. The whale made 74 deep dives greater than $100 \mathrm{~m}$ in this period. However, the profiles of the first 2 dives were shorter (18.1 and $11.3 \mathrm{~min}$ ) and shallower (488 and $384 \mathrm{~m}$ ) than those of following dives, and the surface time between them was relatively short (5 min). Therefore, we suspect that they may have been influenced by the tag deployment and so have removed these data from further analyses.

The whale made deep dives down to 400-1200 m almost the entire day during the tagged period (Fig. 1).
During the afternoon and evening of each day, there were periods of time $(4.2,2.9$, and $1.3 \mathrm{~h})$ during which the whale remained near the surface and did not make deep dives (Fig. 1). Outside of these periods, the whale showed a very regular pattern of dives of 30 to $45 \mathrm{~min}$ duration, and ca. 8 min surfacings. Most dives were 30 to 45 min long, with a mean of 36.2 min (Fig. 2a, Table 1). Maximum dive-depth distribution was bimodal and dives to depths ca. $800 \mathrm{~m}$ were scarce (Fig. 2b).

Mean dive duration was not different between day and night (day, $\bar{x}=37.3, \mathrm{SD}=4.08$; night, $\bar{x}=34.5 \mathrm{~min}$, $\mathrm{SD}=7.73$; $t$-test, $\mathrm{p}=0.051$ ), but the statistical power was only 0.49 ( $51 \%$ chance of a Type II error) and the result is not conclusive. On the other hand, maximum depth was deeper during the daytime (day, $\bar{x}=859.5$, $\mathrm{SD}=234.3$; night, $\bar{x}=709.3 \mathrm{~m}, \mathrm{SD}=287.6$; $t$-test, $\mathrm{p}=$ 0.018 ).

Almost all dives were U-shaped, with a distinct bottom part. In most of the U-shaped dives, the whale was very active at the bottom in terms of both changes in depth and velocity (Fig. 3a). Furthermore, there were some bursts in speed during the bottom periods, suggesting predation events. Four dives had a very inactive bottom part, in both depth and velocity (Fig. 3b), and relatively shallow $\mathrm{V}$-shaped dives were observed 3 times (Fig. 3c).

During the extended surface time on the first day, the whale was quite active at first. In this period we observed whales of the group coming together into a tight cluster and interacting with one another (i.e. socializing behavior, Whitehead \& Weilgart 1991). After that the velocity data became very low, suggesting inactivity and resting behavior. Similar profiles with active and inactive velocity records were observed in the surface time of the second and third days (Fig. 1).

The whale spent $80 \%$ of its total time in long deep dives with an active bottom part, and no clear diurnal pattern of dive behavior was observed (Fig. 1). It should be noted that the behavior patterns, other than

Table 1. Physeter macrocephalus. Dive parameters of the sperm whale. Means \pm SD and ranges are shown for 3 different dive types. Three extremely long surface periods are excluded from the post dive surface time

\begin{tabular}{|lccccccc|}
\hline Dive type & $\mathrm{n}$ & $\begin{array}{c}\text { Duration } \\
(\mathrm{min})\end{array}$ & $\begin{array}{c}\text { Maximum } \\
\text { depth } \\
(\mathrm{m})\end{array}$ & $\begin{array}{c}\text { Bottom } \\
\text { time } \\
(\mathrm{min})\end{array}$ & $\begin{array}{c}\text { Post-dive } \\
\text { surface time } \\
(\mathrm{min})\end{array}$ & $\begin{array}{c}\text { Descent } \\
\text { rate } \\
\left(\mathrm{m} \mathrm{s}^{-1}\right)\end{array}$ & $\begin{array}{c}\text { Ascent } \\
\text { rate } \\
\left(\mathrm{m} \mathrm{s}^{-1}\right)\end{array}$ \\
\hline Dives with active bottom periods & 65 & $37.4 \pm 4.23$ & $844.1 \pm 238.7$ & $17.5 \pm 5.84$ & $8.5 \pm 2.23$ & $1.33 \pm 0.24$ & $1.27 \pm 0.26$ \\
& & $26.9-46.2$ & $408-1192$ & $2.9-27.3$ & $3.6-18.2$ & $0.73-1.76$ & $0.45-1.76$ \\
Dives with inactive bottom periods & 4 & $32.5 \pm 1.21$ & $492.0 \pm 74.6$ & $19.8 \pm 2.91$ & $9.1 \pm 5.85$ & $1.40 \pm 0.13$ & $1.13 \pm 0.07$ \\
& & $30.7-33.3$ & $424-592$ & $17.2-22.9$ & $5.7-17.9$ & $1.29-1.52$ & $1.06-1.24$ \\
V-shaped dive & 3 & $16.8 \pm 4.03$ & $282.7 \pm 69.9$ & $2.5 \pm 2.25$ & $6.8 \pm 1.87$ & $0.85 \pm 0.05$ & $0.67 \pm 0.43$ \\
& & $13.2-21.1$ & $224-360$ & $1.1-5.12$ & $5.2-8.85$ & $0.80-0.89$ & $0.30-1.14$ \\
Total & 72 & $36.2 \pm 5.89$ & $801.1 \pm 264.9$ & $17.0 \pm 6.38$ & $8.4 \pm 2.50$ & $1.33 \pm 0.25$ & $1.23 \pm 0.28$ \\
& & $13.2-46.2$ & $224-1192$ & $1.1-27.3$ & $3.6-18.2$ & $0.73-1.76$ & $0.30-1.76$ \\
\hline
\end{tabular}




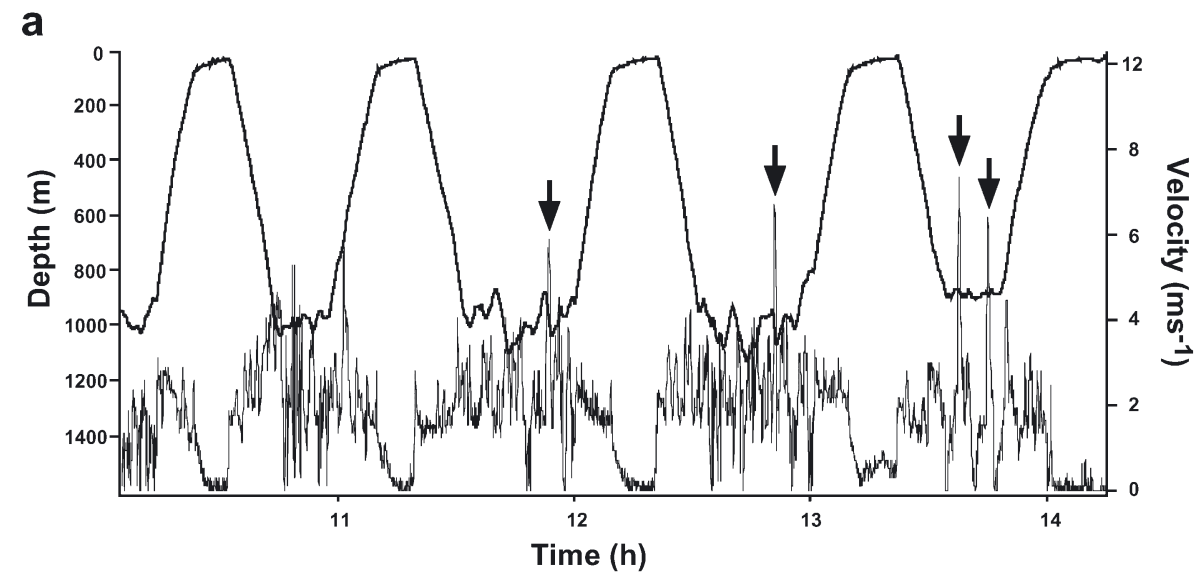

b

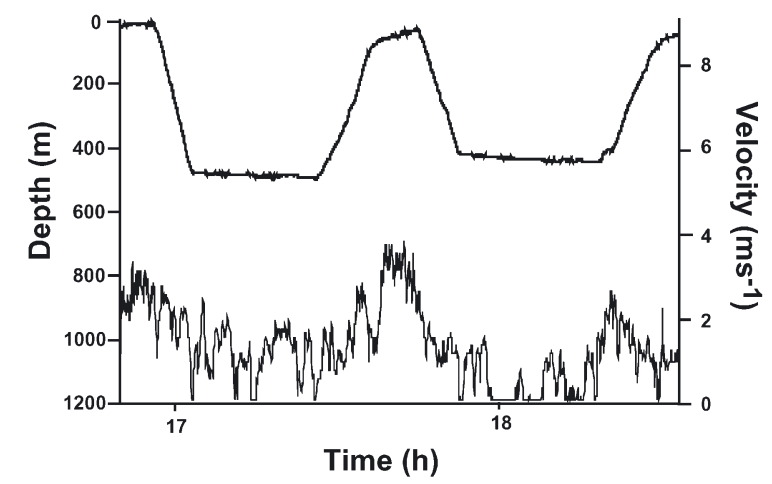

C

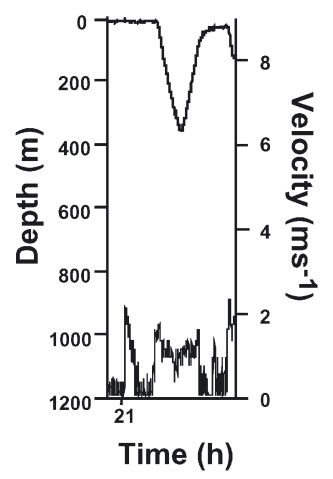

Fig. 3. Physeter macrocephalus. Dive depth and velocity profiles of (a) dives with active bottom period, (b) dives with inactive bottom period, and (c) V-shaped dives. Thick line: depth; thin line: velocity; arrows: bursts of velocity

dives with active bottom periods, appeared in series, except 1 V-shaped dive (Fig. 1). Before the whale started regular dives with active bottom periods, it made different types of dive.

Discussion. The previous tagging studies also suggested that the deep dives of sperm whales were for foraging (Watkins et al. 1993, 2002). The whale was found to change both depth and velocity frequently during the bottom time (Fig. 3a). This strongly suggests that the whale took an active search strategy in foraging. Rice (1989) reviewed the possible feeding strategy for this species; sit-and-wait, active search with tactile sense, and active search with echolocation. Recently, Fristrup \& Harbison (2002), who doubted the echolocation efficiency for squids, hypothesized that sperm whales use vision and search for silhouetted prey against the lighter upward water or lure the prey by stimulated bioluminescence. The present results support neither the sit-and-wait nor luring behavior, where swimming is at a steady speed. The bursts in velocity during the bottom period suggest the whale sometimes vigorously chased prey (Fig. 3a). The bursts lasted ca. 30 to $40 \mathrm{~s}$, and the whale swam ca. 150 to $250 \mathrm{~m}$ during this period. This suggests that the whale detected the prey from this distance by echolocation or vision.

There were a few dives with a very inactive bottom part (Fig. 3b). In pinnipeds, dives with a flat bottom part were thought to be for benthic feeding using the sit-andwait strategy (Le Boeuf et al. 1992, Lesage et al. 1999). If this type of dive was used for foraging, it is expected that its duration should be longer than those of dives with active bottom periods, because it requires less energetic cost (Le Boeuf et al. 1992, Crocker et al. 1997). However, the dives with flat bottom phases were not longer than those with active bottom phases (Table 1), suggesting that they may not be associated with foraging but instead may function for resting or food processing (Le Boeuf et al. 1992, Crocker et al. 1997). This type of dive was recorded on the second and third day, immediately following the long surface time (Fig. 1). The inactive part of the surface time was much shorter on these 2 days (1.0 and $0.3 \mathrm{~h}$, respectively) than that on the first day (3.3 h, Fig. 1). This also supports the belief that these flat bottom dives are for resting. The sperm whales may rest at depth as well as at the surface, and not all of their long dives are necessarily used for foraging.

The tagged whale spent $80 \%$ of its time in foraging dives (Fig. 1). This agrees with radio tag data from the Caribbean (77 to $80 \%$, Watkins et al. 1999) and observations from the Galapagos Islands and in the Azores (75 to $80 \%$, Whitehead \& Weilgart 1991, Gordon \& Steiner 1992). The dive depths tended to be somewhat shallower at night. This tendency was not observed in the sperm whale tagged in the Caribbean (Watkins et al. 2002), suggesting different vertical distribution or behavior of the prey between the habitats.

Northern bottlenose whales Hyperoodon ampullatus are also known as deep divers, and Hooker \& Baird (1999) reported diving profiles obtained by a suctioncup-attached TDR tag. Although their average maximum depth of long deep dives was deeper than that of sperm whale dives with an active bottom period, aver- 
age duration and ascent and descent rates are similar. This means that the bottom time might be shorter in the bottlenose whale, but a different definition of 'bottom' hinders a direct comparison. The dive profiles also seem to be different. The long dive profiles of bottlenose whales are rather V-shaped compared with those of sperm whales, even in their shallow dives of ca. 800 to $1000 \mathrm{~m}$. Moreover, changes of depth record at the bottom of dives are much larger in the sperm whale. Although both species are deep divers, their pattern of foraging and use of deep water habitat appears to be different.

Acknowledgements. We thank Nanki Marine Leisure Service, who provided their boat as the research platform. A. Hasegawa, K. Kimura, Minamchita Beachland Aquarium, Nanki Air Service, Taiji Whale Museum, I. Takahashi, and Toba Aquarium helped us in the filed work. A. Hayano determined the sex of the tagged whale. R. W. Baird and S. K. Hooker instructed us on tag design and deployment methods, and gave us many suggestions on the project and on the manuscript. Three anonymous reviewers provided helpful comments on the manuscript. This project was partially supported by the grants-in-aid from the Iwate Prefectural Government and Ministry of Education, Culture, Sports, Science, and Technology of Japan.

\section{LITERATURE CITED}

Baird RW, Ligon AD, Hooker SK, Gorgone AM (2001) Subsurface and nightime behaviour of pantropical spotted dolphins in Hawai'i. Can J Zool 79:988-996

Baird RW, Borsani JF, Hanson MB, Tyack PL (2002) Diving behavior of long-finned pilot whales in the Ligurian Sea. Mar Ecol Prog Ser 237:301-305

Beale $\mathrm{T}$ (1839) The natural history of the sperm whale. John van Voorst, London (reprinted in 1973, The Holland Press, London)

Blackwell SB, Haverl CA, Le Boeuf BJ, Costa DP (1999) A method for calibrating swim-speed recorders. Mar Mamm Sci 15:894-905

Boyd IL, Arnbom T (1991) Diving behavior in relation to water temperature in the southern elephant seal: foraging implication. Polar Biol 11:259-266

Crocker DE, Le Boeuf BJ, Costa DP (1997) Drift diving in female northern elephant seals: implications for food processing. Can J Zool 58:27-39

Editorial responsibility: Otto Kinne (Editor),

Oldendorf/Luhe, Germany
Fristrup KM, Harbison GR (2002) How do sperm whales catch squids? Mar Mamm Sci 18:42-54

Gaskin DE (1967) Luminescence in a squid Moroteuthis sp. (probably ingens Smith) and a possible feeding mechanism in the sperm whale Physeter catodon L. Tuatara 15: 86-88

Gordon J, Steiner L (1992) Ventilation and dive patterns in sperm whales, Physeter macrocephalus, in the Azores. Rep Int Whal Comm 42:561-565

Hooker SK, Baird RW (1999) Deep-diving behaviour of the northern bottlenose whale, Hyperoodon ampulatus (Cetacea: Ziphiidae). Proc R Soc Lond Ser B Biol Sci 266: 671-676

Le Boeuf BJ, Naito Y, Asaga T, Crocker D, Costa DP (1992) Swim speed in a female northern elephant seal: metabolic and foraging implications. Can J Zool 70:446-458

Lesage VL, Hammill MO, Kovacs KM (1999) Functional classification of harbor seal (Phoca vitulina) dives using depth profiles, swimming velocity, and an index of foraging success. Can J Zool 77:74-87

Mullins J, Whitehead H, Weilgart LS (1988) Behaviour and vocalizations of two single sperm whales, Physeter macrocephalus, off Nova Scotia. Can J Fish Aquat Sci 45: $1736-1743$

Norris KS, Harvey GW (1972) A theory for the function of the spermaceti organ of the sperm whale (Physeter catodon L.). NASA Spec Publ 262:397-417

Rice DW (1989) Sperm whale Physeter macrocephalus Linnaeus, 1758. In: Ridgway SH, Harrison R (eds) Handbook of marine mammals, Vol 4. River dolphins and the larger toothed whales. Academic Press, San Diego, p 177-233

Takahashi I (2001) Relationship between occurrence of sperm whale and oceanographic conditions in Kumano Sea, Japan. Master of Bioresources thesis, Mie University, Tsu

Watkins WA, Moore KE, Tyack P (1985) Investigations of sperm whale acoustic behaviors in the southeast Caribbean. Cetology 49:1-15

Watkins WA, Daher MA, Fristrup KM, Howald TJ, Notarbartolo de Sciara G (1993) Sperm whales tagged with transponders and tracked underwater by sonar. Mar Mamm Sci 9:55-67

Watkins WA, Daher MA, DiMarzio NA, Samuels A and 6 others (1999) Sperm whale surface activity from tracking by radio and satellite tags. Mar Mamm Sci 15:1158-1180

Watkins WA, Daher MA, DiMarzio NA, Samuels A, Wartzok D, Fristrup KM, Howey PW, Maiefski RR (2002) Sperm whale dives tracked by radio tag telemetry. Mar Mamm Sci 18:55-68

Whitehead H, Weilgart L (1991) Patterns of visually observable behaviour and vocalizations in group of female sperm whales. Behaviour 118:275-296

Submitted: October 29, 2002; Accepted: April 9, 2003

Proofs received from author(s): July 31, 2003 